\title{
The Integration of Life and Art: Zhu Ming's Sculptural Arts
}

\author{
Jingyang Xia \\ School of Art and Design \\ Wuhan University of Science and Technology \\ Wuhan, China
}

\author{
Ting Li \\ School of Art and Design \\ Wuhan University of Science and Technology \\ Wuhan, China
}

\begin{abstract}
In the history of Chinese art in the 20th century, Chinese and Western cultures have constantly collided with each other and been integrated. Integrating Chinese and Western art creation concepts was a natural choice for a generation of Chinese artists who have received the edification of Chinese and Western cultures and arts. They had an innate reverence for the Chinese traditional culture with profound artistic conceptions. However, they also had a keen appreciation and deep resonance of the Western art, especially the modern art that emphasizes expression of personalities. Zhu Ming is a representative of this group of artists. His talent, diligence and good inheritance from his teacher enable him to fully realize his potential on the basis of the predecessors. He has adhered to the perseverance spirit in art from his apprenticeship to artistic turning, from native land sentiment to Taiji feelings, and from colors of the world to the natural creation. He compares art to self-cultivation, thus showing the artistic realm of pursuing natural laws and finally returning to his heart. Zhu Ming's sculptures have drawn their materials from real life, expressed the philosophy of life, embodied natural charm, absorbed the spirit of nature, had chaotic and uniform expression forms, and shaped into large blocks as if being cut with swords and axes, which has shown the relaxed attitude of $Z$ hu Ming in creating the sculptures. Zhu Ming has created a series of sculptures that contain both profound oriental cultural connotations and unique characteristics. And he is a model of heavyweight in the contemporary inheritance and development of Chinese sculpture art.
\end{abstract}

\section{Keywords—life; Zhu Ming; art; nature; sculpture}

\section{INTRODUCTION}

Zhu Ming is good at using the simplest elements such as points, lines, and faces, and greatly purifying them in his works. He likes to present these elements in geometric forms. His sculptures are usually shaped into large blocks, and the turning lines of the faces are basically tough straight lines. However, from Zhu Ming's sculptures, we can still see the vitality of life through the majestic blocks, which stems from his self-cultivation in life and art. For the artists, if they don't want to lose themselves, they should live a simple and natural life, return to the nature and maintain an innocent and pure heart. So his works are not simple. They are the refinement of life and nature. He integrates life and art like casting an alloy, and exploring the origins of art and life becomes the essence of his life.

\section{ZHU MING'S APPRENTICESHIP}

Mr. Zhu Ming was born in Taiwan in 1938. He lived in a relatively poor family. After he graduated from elementary school, he dropped out of school. But he was fortunate in his life and had the opportunity to study wood carving from $\mathrm{Mr}$. $\mathrm{Li}$ Jinchuan at the age of 15 . Mr. Li Jinchuan is a folk engraver who mainly carved wooden statues of local temples. Therefore, Mr. Zhu Ming learned from this master and mastered the superb woodcut art. Mr. Zhu Ming has great artistic talent and unremitting pursuit of art, and at that time his career limited his artistic development. Mr. Li Jinchuan said bluntly to Zhu Ming that he could not teach him more and encouraged him to pursue his own career. During his period of learning from Mr. Li Jinchuan, Zhu Ming has learned the woodcut sculpture technique that is benefit for him for a lifetime. The long-term study of the temple statues also had a certain influence on Zhu Ming's future sculpture works.

In 1968, Zhu Ming ended his original business with the encouragement of his wife and began to learn from Professor Yang Yingfeng, the pioneer of modern sculpture in Taiwan. At that time, Mr. Yang Yingfeng was an outstanding practitioner of the modern art movement in Taiwan. He advocated "Chinese modernity" and emphasized "the oriental spirit in modern art". He highly praises the artistic style and philosophy of the Wei, Jin and Southern and Northern Dynasties and longs for the artistic realm of traditional aesthetics. He believes that Chinese artists can draw artistic spirit from the traditional culture of Confucianism, Buddhism and Taoism to create completely different works of art. His sculptures present a strong Chinese style, as crystal and gentle as Song porcelain, and as beautiful as celestial beings. He greatly promoted Zhu Ming's development on the technical and artistic level. He taught Zhu Ming "two desertions". One is to "desert" the original pure skills, abandon the form, and find his own artistic language and expression way. The second is to desert the style of Yang Yingfeng, not to learn from him, but to do Zhu Ming first. The name "Zhu Ming" was from Mr. Yang Yingfeng. "Ming" has the meaning of "remember". Mr. Yang Yingfeng hopes that the world can remember Zhu Ming and his works. From 1968 to 1976 , in the long period of time with Yang Yingfeng, Zhu Ming's aesthetic thoughts were sublimated, and his artistic vision was more open. He truly understood "how" and "what" he should "carve" as an artist and gradually grew into a famous sculptor from a folk artist. 


\section{SCULPTURES OF ZHU MING}

\section{A. Distinctive Personal Style}

Zhu Ming's sculptures have always had a distinct personal style, and the formation of the style is closely linked to Zhu Ming's learning from his teachers, conducting "selfcultivation" in art creation and honest attitude towards art. Zhu Ming's early works are local-themed, and his early style was shaped by his farming experience in his childhood and the wood carvings he first learned from Mr. Li Jinchuan. Most of his early works are partially realistic, and he combined the spirit of traditional Taiwanese wood carvings and modern sculptures he had learned, which can be seen in his works such as "Cattle", "Shepherd Boy", "Kong Ming", etc. Later, he was influenced by Mr. Yang Yingfeng, and integrated Chinese philosophy in his works and gradually formed his own unique style. Under the devoted teaching of Professor Yang for more than ten years, Mr. Zhu Ming's aesthetic accomplishments have been sublimated and his vision has become wider. The first is the prajna thought of Mahayana Buddhism. It emphasizes unconstrainedness and advocates freedom and communications with the universe. The second is the combination with nature and the pursuit of the unity of nature and man. It emphasizes respecting nature, learning from nature, and loving nature. The last is to advocate the simple and unadorned aesthetics and the most concise way to show the charm of the works. Therefore, Zhu Ming combined the eclectic creative techniques with the themes of natural life in most of his sculptures. The works also reveal a little Buddhist mood or look sincere. Therefore, he is considered to be a representative of Taiwan's artistic creation and has gradually become a sculpture master (seeing "Fig.1").

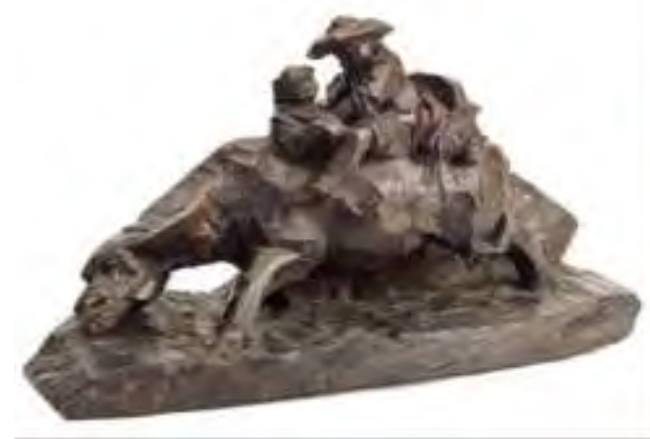

Fig. 1. "Shepherd Boy".

\section{B. The Themes of Creation That Stem from Life}

Mr. Zhu Ming's sculptures are welcomed and loved by the public, and even attract many people who do not know much about art and sculpture. This reflects that his works can satisfy the artistic needs of general people. Most of the modern rookie artists need to take the academic elite route to come out. This kind of route is safe and secure, and almost impossible to cause controversy, but at the same time it is easy for the artists to restrain themselves in such route. In contrast, Mr. Zhu Ming's success is inseparable from his "grassroots" which is in line with the public's psychology. At that time, his artistic creation changed from the local-themed "Buffalo" to the steady and honest "Tai Chi" series. When people thought that he would continue to create artworks in this successful style, he unexpectedly created a very dynamic and life-like "Sports" and "The World" series. When people began to respectfully call him the venerable $\mathrm{Zhu}$, he again created a new large series of works named "The Army". The development of Zhu Ming's artistic themes is of course derived from his artistic innovation, and it is also inseparable from his inner local views and worldly sentiment. The "Tai Chi" series seems to be serious, but in fact it is more of Zhu Ming's perception of Tai Chi in the process of practicing Tai Chi in many years. Since the 1980s, the interesting series of "Female Relatives" have been created, which depicted simple human feelings and various human relationships. The free and pleasant series of "The World" summarized many social phenomena in life, and is an extension of the tastes of secular life, which is both surprised and reasonable. As described above, the series of "The World" contains not only ancient but also modern models, not only Chinese but also foreign models, and there are Eastern gentlemen as well as rough and lively Western women. Some characters are standing and some are sitting, some are straight and some are oblique, all showing a self-satisfied expression and expressing an optimistic outlook on life, which are the products of his observation and reflection on real life and have a strong sense of the times. Choosing this kind of themes that fits the real life well reflects his thinking about the living conditions of modern urbanites. These colorful sculptures in "The World" series with the warning feature are the beginning of Zhu Ming's creation. Henry Moore said, "The observation of nature is part of the artist's life, which can expand his knowledge and help him maintain the feeling of freshness, preventing him from creating through the fixed model and helping him get inspirations". From this we can see that the themes of creation must come from the artists' seeing, hearings and feelings in life, and the materials from life need to be remembered by the artists in their heart and then expressed in appropriate external forms in the process of being turned into art. Otherwise, the artworks cannot really touch the viewers. In the 1980s, Mr. Zhu Ming began to explore the sculptural art again, which has lasted for more than ten years. He said: "I don't like to repeat. I like to make innovations. My sculpture series are also very life-oriented, and my creative attitude is casual and free (seeing "Fig.2")."

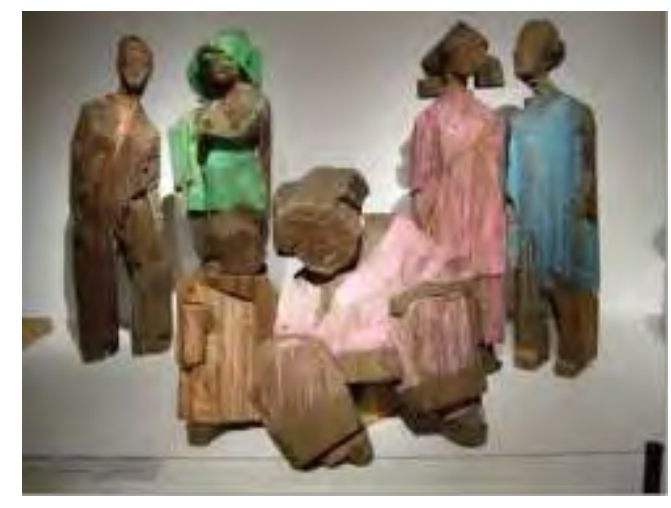

Fig. 2. "The World Series - Female Relatives". 


\section{The Bold Use of Materials}

As early as in the 1970s, Mr. Zhu Ming began to try to use a variety of materials to make sculptures, which can also reflect from the side that Mr. Zhu Ming has been looking at various materials from the perspective of sculpture. In his creation, Zhu Ming used a variety of materials and techniques. In the eyes of sculptors, the raw materials should be solid and strong. The materials used by Zhu Ming include not only woods and stones, but also clay, sponge, cast copper, stainless steel and so on. Because of his local feelings and wood carving foundation, most of Zhu Ming's early works are wood carvings. The material of woods gives people a feeling of intimacy, and is also easier to engrave, easy to draw, and has a strong living and natural sense. This is also a factor that the early works are easily accepted by the public. In addition to wood carvings, the Tai Chi series also has a large number of bronze and stone carvings. The wood carvings are gentle and simple, and it is easy to highlight the "softness" of Taijiquan and the rich spiritual connotation through the material of woods. Bronze and stone carvings can reflect the power and vigorous and firm imposing manner of Tai Chi. Since the artistic themes came from the natural life, whether the works were made of woods or stones, the viewers can feel a natural spiritual power. The first series of "The World" was all carved out of wood, which contains a completely different emotional thinking from the "Tai Chi" series. The material of the works is rough and without any modification, which makes people feel that the works were randomly cut by knives and axes. The surface traces are interesting, and these works contain the original essence of life (see "Fig.3"). Through the materials, the characters of the works have become more sluggish and dull, which is more in line with the theme of the "The World" series, in which people are walking alone in the corner of the city and watching the world with cold eyes. The characters in the "Happy World" series are much more humorous and joyful. The style is different from that of "Female Relatives". In the process of creating works with this theme, materials played a vital role. The works made of copper casting seem to be simple, natural, and interesting. And works made of stainless steel reflect modern civilization and technologies. The sponge copper used in the "The World Series" is made by tying the sponge with ropes and integrating it with the bronze. The manufacture of materials is full of challenges, but $\mathrm{Mr}$. Zhu Ming invented a special machine to process and manufacture these materials. He believes that materials have their own characters and are reactive, so the creation of sculptures is a process of control and compromise. (See "Fig. 4").

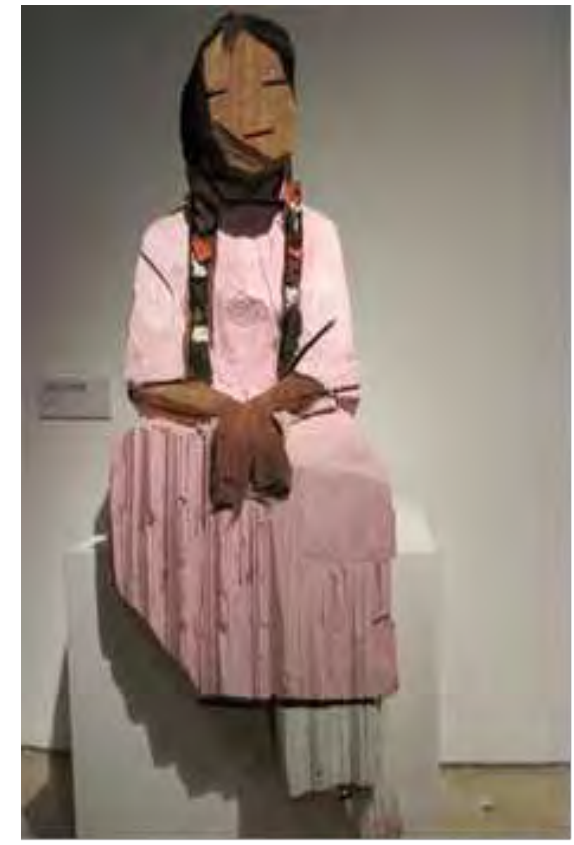

Fig. 3. "The World Series (Wood)".

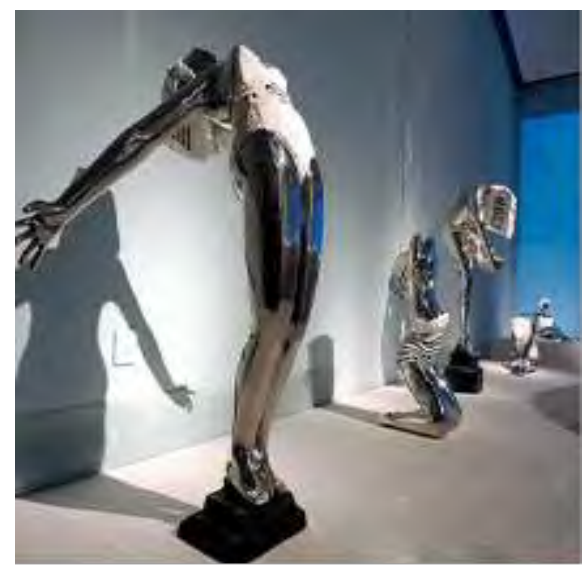

Fig. 4. "The Happy World Series (Stainless Steel)".

\section{Unique Expression Techniques}

In his long creative career, his expression techniques have changed from being tangible to being intangible. At the beginning of the creation of wooden sculptures, he basically used the knives and axes to cut the raw materials. But later he switched to use the hacksaws or electric saws to chainsaw the woods and then engraved them along their textures. Or he would cut the woods directly with a knife or axe, leaving wood textures on the surface of the woodcarvings, so that the natural textures of the material can be directly transformed into part of the sculptures, thus increasing the vitality and expressive power of the characters. For example, in the "Tai Chi" series, the work of "Making Movements" was cut with a knife or axe directly at the turning points of the character movements, which not only has not destroyed the movements, but also added a vigorous, firm and unique taste to the sculptures. The character movements he created in the series of "The World" 
are usually slightly exaggerated and dramatic, and it is wondered that if he has drawn inspiration from some traditional dramas in Taiwan. He made his wooden works partially colored, which is inspired by the colorful surfaces of the ancient artifacts. The surface of the wood was painted with the colors of bright red, green and blue, which makes the creation method livelier and freer. The power of the Tai Chi series comes from the combination of Chinese traditional culture and modern art techniques, and it has achieved a delicate balance between the two. The traditional Taijiquan dynamic movements are combined with the concise and blocky sculptural techniques, and the sculptures show strong oriental charm as well as impressive vitality. The "Tai Chi Arches" of the "Tai Chi" series has continued Zhu Ming's typical style. They don't have the typical features of a certain doctrine or genre, but can always present a beauty of the forms when putting into a public space. Zhu Ming's works all present the Taoist style. The combination of yin and yang, false and true, dynamic and static expressed on the sculptures not only shows distinct personalities, but also reflects Zhu Ming's artistic attainments. In his sculptural works, the emotional expression and spiritual pursuit has complemented each other, which has been presented in a simple form and finally returned to the original. In this way, in the process of artistic creation, simplicity and complexity are mutually reinforcing and compromising each other, reflecting the essence of art: it can be abstract, but also can be concrete. In general, Mr. Zhu Ming's artistic technique is to sculpt rather than shape. Sculpting and cutting a complete piece of original material is very different from piling up small pieces of materials and shaping them into a complete one. The difference between the two is that the former is to carefully carve the original material from big to small and the latter is to pile up pieces of materials from small to large (See "Fig.5").

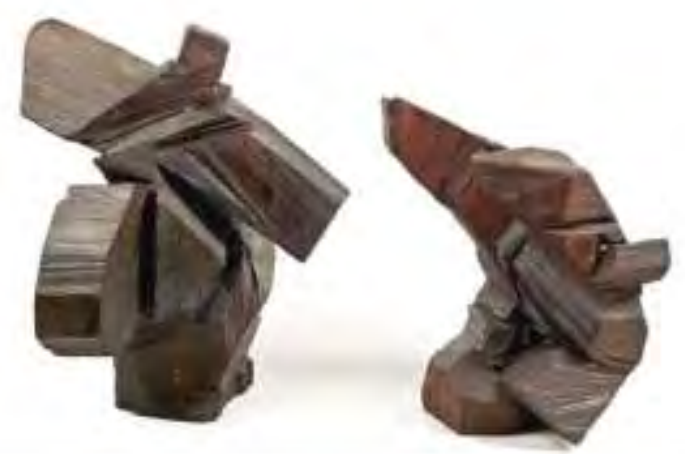

Fig. 5. "Taichi Series — Making Movements".

\section{CONCLUSION}

The artistic achievements of Zhu Ming are inseparable from his life experience and his free and unruly art style. Every artwork of Zhu Ming is closely related to his life, and from the artworks, we can feel a strong living atmosphere. Although art is not the whole of his life, he has injected his life experiences into his artworks, making them alive.
It can be seen from Zhu Ming's sculptures that combining life with artistic creation, integrating the materials and creative content, and combining innovation with honest creation is an art treasure that contemporary artists can learn from. Incorporating personal feelings and thoughts from life into the artistic creation can make the works express sincere feelings, have rich emotions, and have vivid images, so that it is more likely for the viewers to resonate with the works. Secondly, the artists are very familiar with what they have felt, seen and done in their life and often remember them in heart, so it is easy for them to externalize these feelings and experiences in appropriate art forms, and it is more likely to form their own unique styles, free from the formal artificial art creation. The materials should be suitable for the selected themes and techniques. More relevant are they to the theme, more able will they be to reflect the connotation of the work. Artists should be honest while they are trying to make innovations in their artworks. They should ask themselves, "Are you creating for art or for gimmicks and wealth? Are you pursuing art or catering to the market?" Only by being honest with themselves, being honest with the public, and being honest with the art can they be artists rather than craftsmen and even businessmen.

\section{REFERENCES}

[1] Sui Xi. Zhu Ming's simple but great sculptures [J]. Sculpture, No. 5, 2010, P10. (in Chinese)

[2] Li Qing. From Tai Chi to The World, Mr. Zhu Ming, a famous Taiwanese sculptor [N]. Northwest Fine Arts, Journal of Xi'an Academy of Fine Arts, No. 1, 2003, pp.34-35. (in Chinese)

[3] Li Qing. Modern interpretation of the oriental spirit - Discussions on Zhu Ming's sculptural art[J]. Art Research, No. 4, 2002, pp.80-82. (in Chinese)

[4] Lin Gongxiang. The "Chinese spirit" of Zhu Ming's sculptures [J]. Art Life, No. 6, 2006, pp.62-63. (in Chinese)

[5] Mu Jie. From "Local" to "The World" - MingZhu's public sculptures [J]. Public Art, No. 1, 2009, pp.78-81. (in Chinese)

[6] Wang Zhong. Like Nature Themselves - The Great Tai Chi MingZhu's Tai Chi sculptures [J]. Sculpture, No. 3, 2006, pp.19-20. (in Chinese) 